\title{
Projeto Novela: uma abordagem comunicativa $e$ intercultural no ensino de alemão como língua
}

\section{estrangeira}

[Soap opera project soap opera: a communicative and intercultural approach in the teaching of German as a foreign language]

http://dx.doi.org/10.11606/1982-8837223831

Marceli Aquino ${ }^{1}$

\begin{abstract}
This article aims to reflect on communicative and intercultural practices in the teaching of German as a foreign language (GFL). To work with language and culture in an integrated way, focusing especially on the communicative needs of learners, the "soap opera" project was developed during the German Language II course attended by Language undergraduate students of the University of Sao Paulo. This project has proposed a modern reinterpretation of Brazilian soap opera (or telenovela), where students were encouraged to produce episodes, sequential narratives, applying their on growing knowledge in the German language and making use of authentic materials, such as comics, music, WhatsApp messages, videos, among others. By covering all three aspects defined by Weissenberg (2012) focusing on the development of competencies and learning needs, the project has made it possible for the students to feel (co)responsible for their knowledge acquisition process, with positive impact on their motivation and sense of responsibility. Finally, the results suggest that tasks that encourage the use of communicative skills and strategies, besides its potential as a tool for integrative learning, can promote relevant intercultural discussions.
\end{abstract}

Keywords: German as a foreign language; communicative skills; intercultural approach; learning needs.

Resumo: O presente artigo visa refletir sobre práticas didáticas comunicativas e interculturais no ensino de alemão como língua estrangeira. No sentido de trabalhar língua e cultura de maneira integrada, atentando especialmente nas necessidades comunicativas e interesse dos aprendizes, desenvolveu-se o projeto Novela, na disciplina Língua Alemã II, do curso de graduação de Letras da Universidade de São Paulo. Este projeto propôs uma releitura atual das telenovelas brasileiras, onde os aprendizes foram incentivados a produzir os episódios, narrativas sequenciais, aplicando o conhecimento de alemão adquirido e fazendo uso de materiais autênticos, tais como quadrinhos, música, conversas por SMS e WhatsApp, vídeos, entre outros. Ao abarcar todos os três aspectos delimitados por Weissenberg (2012) para um ensino focado no desenvolvimento de competências e necessidades de aprendizagem, o projeto possibilitou que os estudantes se sentissem (co)responsáveis pelo processo de aquisição e transmissão do conhecimento, tendo impactos positivos em sua motivação e senso de responsabilidade. Por fim, os resultados obtidos sugerem que tarefas que incentivam o uso de habilidades e estratégias comunicativas, além do seu potencial

\footnotetext{
${ }^{1}$ Universidade de São Paulo, Av. Prof. Luciano Gualberto, 403, São Paulo, 05508010, Brasil. E-mail: marceli.c.aquino@gmail.com. ORCID: 0000-0003-0518-7639
}

(cc) BY-NC 
AQUINO, M. - Projeto Novela

como ferramenta para uma aprendizagem integrativa, podem promover discussões interculturais relevantes.

Palavras-chave: alemão como língua estrangeira; habilidades comunicativas; abordagem intercultural; necessidades de aprendizagem.

\section{Introdução}

Segundo Vigotski (1998), os significados das palavras precisam ser investigados através do seu uso dentro de um contexto interacional, uma vez que os sentidos são coconstruídos pelos interlocutores na interação. Em consonância com essa conjectura, atualmente os estudos sobre o ensino e a aprendizagem em língua estrangeira (doravante LE) consideram que a interação constitui o principal meio para o desenvolvimento social e cognitivo, e para a aquisição de competência comunicativa. Esta abordagem demanda, portanto, aulas orientadas para as necessidades do aluno, onde ele é o ponto central da prática didática e (co)autor de sua aprendizagem (SCHNEIDER 2010: 70).

Atualmente, a maioria dos livros didáticos em alemão como língua estrangeira (doravante ALE) fundamentam-se no princípio pragmático-funcional, ${ }^{2}$ adotando a abordagem comunicativa e, em maior ou menor grau, a interculturalidade (SCHNEIDER 2010: 69). Essas abordagens partem das experiências, dos conhecimentos, da motivação e das vivências culturais dos estudantes, estabelecendo os objetivos de aprendizagem a partir da pergunta: "O que os alunos em questão precisam e/ou querem saber para utilizar a língua-alvo como meio efetivo de comunicação?”. Assim, é importante ter em mente o conjunto de princípios e objetivos de ensino em ALE, os tipos e necessidades de aprendizagem, as atividades a serem mediadas, bem como o papel dos alunos e professores em sala de aula.

$\mathrm{Na}$ aplicação do princípio pragmático-funcional, o texto (oral e escrito) constitui o ponto de partida, especialmente a utilização de textos autênticos, para promover atividades que levem o aluno ao aprendizado através da linguagem real empregada na cultura-alvo. Além disso, o aprendiz é percebido como um parceiro ativo e deve ser motivado a desenvolver seus conhecimentos de forma consciente (cognitiva) e criativa (SCHNEIDER 2010: 69). Logo, o professor assume a função de mediador e facilitador nos processos da aprendizagem, viabilizando a interação sociocultural.

\footnotetext{
${ }^{2}$ Na perspectiva da linguística pragmática, a linguagem é vista como um aspecto da interação humana, seu objetivo é investigar o que os indivíduos fazem ao utilizarem uma língua para se comunicar (AUSTIN, 1962).
} 
AquINO, M. - Projeto Novela

A demanda por uma metodologia intercultural deu-se pelo desenvolvimento da linguística pragmática e cultural, sendo um reflexo do processo de migração em todo mundo (RÖSLER 2012: 82). Essa perspectiva tem a interação entre o eu e o outro como ponto de partida para as considerações didáticas. Consequentemente, uma abordagem reflexiva com relação à linguagem e cultura (alvo e fonte) desempenha um papel importante no ensino de ALE, permitindo um aprendizado consciente ao reduzir possíveis preconceitos e desenvolver a tolerância.

Logo, as habilidades comunicativas implicam a competência intercultural, isto é, requer o (re)conhecimento e o respeito pelas diferenças interculturais presentes nos comportamentos sociolinguísticos, nas concepções e atitudes, bem como nos valores socioculturais entre as culturas em contato (AQUINO 2018: 276). Nesse sentido, saber estabelecer paralelos interculturais, e estar aberto para aprender não somente sobre, mas, primordialmente, com a cultura do outro e a nossa própria é o principal requisito para desenvolver a competência intercultural, uma qualificação cada vez mais central na vida profissional no mundo atual (SCHNEIDER 2010: 73).

Tendo como apoio as abordagens comunicativa e intercultural, desenvolvemos na disciplina Língua Alemã II (período noturno) de graduação em Letras da Universidade de São Paulo (USP), um projeto extracurricular com a temática de novela (ou telenovela). Nosso intuito era incitar a produção (oral e escrita), desenvolver a criatividade e o uso da língua em diferentes situações, discutir questões interculturais e, especialmente, suprir as necessidades de aprendizagem dos estudantes. Por esse ponto de vista, a própria temática do projeto adveio de atividades realizadas em sala de aula, atendendo a demandas e sugestões dos alunos.

O título Novela se justifica pela semelhança à narrativa do gênero de telenovelas, isto é, episódios seriados em que o seguinte é continuação do anterior, o melodrama, descrição de temáticas cotidianas e o foco em relacionamentos amorosos (MURAKAMI 2015: 11). Segundo Calza (1996), a telenovela é um meio de entretenimento, uma narrativa crônica do cotidiano que representa a realidade do telespectador e desperta emoções. No entanto, as narrativas apresentadas neste projeto se caracterizam essencialmente por sequências de histórias em episódios, não tendo a intenção de refletir inteiramente as características do gênero telenovela, ou imitar novelas já existentes. Dessa forma, os alunos tiveram total liberdade para dialogar com esse gênero e reinterpretá-lo, 
introduzindo materiais, linguagens e eventos que expressassem a sua experiência, necessidades e interesses.

Com o intuito de evidenciar a pertinência do projeto desenvolvido como alternativa didática atual e relevante para o ensino e aprendizagem de ALE, apresentamos neste artigo o trabalho Novela, desenvolvido com estudantes de Letras (licenciatura e bacharelado) em língua alemã. Além de oferecer uma estratégia didática, que lide com aspectos comunicativos e interculturais, pretendemos abrir espaço para a discussão de metodologias e práticas que vão além do material didático, isto é, que considerem as necessidades particulares dos estudantes de língua alemã em cada contexto de aprendizagem. Para isso, nas próximas seções apresentamos a metodologia aplicada, o projeto da novela em si e as conclusões finais.

\section{Metodologia}

A característica essencial de tarefas comunicativas e interculturais é a relação com a vida e cotidiano dos alunos, oferecendo atividades orientadas para resultados (RöSLER 2012: 86). Logo, é essencial a utilização de linguagem autêntica e funcional na língua alvo, onde os aprendizes tenham algo real a dizer. A orientação das tarefas não é, portanto, produzir unidades linguísticas controladas por fenômenos individuais, mas sim formular meios comunicativos holísticos, que considerem o significado e a realização comunicativa.

Weissenberg (2012: 9) apresenta uma perspectiva de ensino que leva em conta a necessidade de aprendizagem dos estudantes: "O que os participantes devem, podem e querem aprender, por que e como?". ${ }^{3}$ Seu trabalho visa discutir as estratégias de aprendizagem em cursos de ALE voltados ao mercado de trabalho (berufsbezogene Deutschförderung) tratando, no entanto, de aspectos relevantes a todos os âmbitos de ensino e aprendizagem de LE. O autor sugere um planejamento de aulas que promova o fortalecimento de competências, tendo o estudante e seu potencial como ponto central. Weissenberg delimita três aspectos que se relacionam entre si: necessidades objetivas (objektive Bedarfe), necessidades subjetivas (subjektive Bedarfe) e necessidades de aprendizagem (Lernbedarfe).

\footnotetext{
${ }^{3}$ Tradução da autora para “Was sollten, können und wollen die Teilnehmenden warum und wie lernen?”.
} 
AQUINO, M. - Projeto Novela

As necessidades objetivas designam enfoques profissionais e suas respectivas exigências comunicativas, estando ainda relacionadas ao contexto do curso, como a quantidade de alunos por turma, os materiais utilizados, a duração das aulas e espaços a serem utilizados para esse fim. Por sua vez, as necessidades subjetivas são orientadas pelas manifestações dos aprendizes, envolvendo desde o material didático até formas sociais (Sozialform) adequadas para as atividades desenvolvidas. Já as necessidades de aprendizagem, ou processuais, evidenciam-se a partir da observação do professor com relação às habilidades e dificuldades dos estudantes, fornecendo indicações quanto à aplicação de estratégias e aos materiais selecionados (WEISSENBERG 2012: 9-11).

Para o desenvolvimento e aplicação deste trabalho, levamos em consideração os três aspectos mencionadas por Weissenberg. Assim, a partir da definição de necessidades, cabe estipular os elementos que serão analisados de acordo com o contexto em foco:

\begin{tabular}{|c|c|c|c|}
\hline Necessidades & Objetivas & Subjetivas & De aprendizagem \\
\hline $\begin{array}{l}\text { Aspectos } \\
\text { considerados }\end{array}$ & $\begin{array}{c}38 \text { alunos } \\
\begin{array}{l}\text { Alunos e currículo do } \\
\text { curso de letras }\end{array} \\
\text { Daf Kompakt } \\
\text { 1h30min aula, três } \\
\text { vezes por semana }\end{array}$ & $\begin{array}{c}\text { Motivação } \\
\text { Necessidades } \\
\text { específicas de } \\
\text { aprendizagem } \\
\text { Tema sugerido pelos } \\
\text { alunos } \\
\text { Discussões } \\
\text { interculturais }\end{array}$ & $\begin{array}{c}\text { Gramática } \\
\text { Vocabulário } \\
\text { Produção } \\
\text { Compreensão } \\
\text { Uso da língua }\end{array}$ \\
\hline
\end{tabular}

Quadro 1: Necessidades e aspectos considerados para o desenvolvimento do projeto de novela Fonte: elaboração do autor.

Mesmo com suas limitações, o curso de alemão na universidade apresenta uma abordagem mais reflexiva sobre o uso do idioma. O projeto pedagógico do curso de Letras da USP procura realçar a diferença entre as disciplinas ofertadas pela universidade e um curso de línguas, evidenciando que o primeiro não visa apenas à aquisição e proficiência em LE, mas uma análise crítica sobre os fatos linguísticos e literários, bem como a sua fundamentação teórica. Ainda, coloca-se como objetivo do curso o desenvolvimento da

\footnotetext{
${ }^{4}$ Segunda, quarta e quinta-feira no período noturno.
} 
AQUINO, M. - Projeto Novela

capacidade de leitura, expressão escrita e oral, considerando as habilidades específicas nas habilitações em Letras Estrangeiras Modernas.

O livro Daf Kompakt neu (A1 e A2) (BRAUn 2016), utilizado na disciplina, introduziu na lição sete ${ }^{5}$ os personagens Lena e Max cuja história chamou a atenção dos estudantes, pela proximidade que se criou entre eles. A frequente menção sobre um possível relacionamento amoroso entre os dois originou o planejamento da novela, cujo intuito seria dar continuidade à história amorosa de Max e Lena, já que os personagens não apareceriam nas próximas lições. Assim, a motivação e interesse para este trabalho adveio diretamente do contexto de sala de aula e seus indivíduos.

Ainda, os estudantes manifestavam frequentemente interesse em discutir sobre temas interculturais. A temática da novela nos pareceu ideal nesse contexto, pois possibilitou mediar aspectos da língua e cultura alemã através de uma narrativa consolidada na televisão brasileira (MURAKAMI 2015: 11). Durante todo o processo, os aprendizes se mostraram envolvidos na integração de questões interculturais, como pesquisar nomes comuns alemães, situações sociais, usos de tratamento formal e informal, vestimenta, alimentação, nomes de ruas e lojas, ambientes e formas de interação entre pessoas, entre outros.

Além dos conteúdos linguísticos exigidos pelo currículo da disciplina, o projeto de novela possibilitou a aplicação de conhecimentos adquiridos acerca das partículas modais alemãs (doravante PMs: aber, denn, doch, ja, eigentlich e wohl) levando em consideração as suas regras gramaticais, suas funções comunicativas e a utilização em diferentes contextos (AQUINO 2017: 164). Não obstante, os alunos também pesquisaram sobre gírias, expressões e usos informais da língua, conteúdos que nem sempre são tratados nos livros didáticos.

O modelo de projeto viabiliza, portanto, o desenvolvimento das quatro habilidades, incentivando a aquisição através de estratégias comunicativas. Consequentemente, aulas interativas requerem a participação ativa dos estudantes, uma atmosfera agradável e um clima de confiança para a concretização do aprendizado. Além disso, essa tarefa pode incentivar o espírito colaborativo dos participantes (professor e alunos), visto que a comunicação e a aprendizagem são co-construídas. Para a

\footnotetext{
${ }^{5} \mathrm{Na}$ disciplina Língua Alemã II foram trabalhadas as lições sete e oito do livro Daf Kompakt neu A1 e as lições de nove até 12 do livro A2.
} 
AQUINO, M. - Projeto Novela

organização e aplicação do trabalho da novela, nos baseamos no design de projetos sugerido por Krumm (1991):

1. Ter um objetivo concreto que permita usar a linguagem em uma capacidade comunicativa, descobrindo e experimentando algo novo;

2. Professores e alunos atuam como coautores do planejamento e execução. A língua fornece os meios que serão usados para realizar a tarefa;

3. Inclusão do mundo exterior na sala de aula, para que seja possível experimentar com a língua aprendida de maneira concreta;

4. Incentivar a postura independente do aluno, usando ferramentas disponíveis, como dicionários e gramáticas, computador, microfone ou câmera;

5. Apresentação dos resultados (dentro ou fora de sala). O trabalho com a língua (correção de erros, gramática, escrita) ocorre sob a forma de revisão, ou seja, a sala de aula torna-se uma "oficina".

A organização do projeto foi previamente discutida com os alunos. Chegamos à conclusão que cada grupo escolheria a abordagem e o material de sua escolha, no entanto, era necessário que as histórias ocorressem em sequência. As apresentações ocorriam ao final da aula, às segundas e quintas de semanas intercaladas, com um intervalo de uma semana entre elas. Além disso, os estudantes contavam com a ajuda da professora para modificações necessárias na linguagem. ${ }^{6}$

Os alunos foram incentivados a utilizar mídias e diferentes meios para o desenvolvimento e a apresentação das narrativas. Os materiais escolhidos pelos grupos foram: quadrinhos, vídeos, animações, mensagens de WhatsApp, leituras dramatizadas e música. Em todos os casos foi elaborado um texto escrito.

Finalmente, defendemos que em aulas de ALE a língua seja treinada, tanto quanto possível, com suas formas típicas de comunicação. Os aspectos linguísticos não devem ser tratados de maneira isolada, mas incorporados em um contexto situacional autêntico,

\footnotetext{
${ }^{6}$ Levando em conta o nível de conhecimento de língua dos alunos em questão (A2), considerou-se necessária a correção de erros gramaticais mais evidentes. No entanto, mantiveram-se, o máximo possível, as escolhas e estilos escolhidos pelos aprendizes.
} 
AQUINO, M. - Projeto Novela

dirigido a um resultado compreensível (KüHN 2010: 1253-1254). Nessa perspectiva, projetos são trabalhos direcionados a um objetivo ou produto, dentro de um contexto de ensino institucionalizado, nos quais os processos de resolução de problemas, ou de negociação, formam eixos educacionais (SCHART; LEGUTKE 2012: 1172).

\section{Novela}

Como mencionado anteriormente, para o desenvolvimento de atividades com orientação comunicativa e intercultural, é imprescindível levar em consideração diversos aspectos, como o material empregado, o contexto, as necessidades, as expectativas e o processo de aprendizagem dos participantes (RÖSLER 2012: 85). Tanto a mediação como os materiais precisam ser motivadores, fortalecendo a autoconfiança dos estudantes e permitindo a aquisição de conteúdos linguísticos.

A novela teve início com a lição sete (a primeira a ser trabalhada) do livro Daf Kompakt neu Al (BRAUN 2016), que apresentava a temática de Café Waschsalon, lavanderias onde as pessoas lavam suas roupas sozinhas e têm acesso a outros serviços, como internet, bar, cafeteria, concertos etc. Esse modelo de negócio é bastante comum na Alemanha, mas não no Brasil, o que causou um estranhamento inicial nos alunos, afinal, quem vai à lavanderia para conhecer pessoas, tomar uma cerveja e ouvir música? Nesse sentido, para a reflexão dos aspectos interculturais dessa temática, além do livro didático, lemos textos jornalísticos autênticos sobre a relevância destes estabelecimentos na cultura alvo e encontramos lavanderias em São Paulo com o mesmo conceito de negócio.

Essa temática influenciou discussões interculturais relevantes, pois os estudantes começaram a compreender a importância desses espaços nas duas sociedades, como a economia de tempo e dinheiro, pois lavanderias com atendentes são geralmente mais caras e, ao esperar a roupa lavar, o cliente tem a possibilidade de navegar na internet, comer algo, ouvir música e socializar. Além disso, em grandes cidades, como São Paulo e Munique (cidade mencionada no artigo jornalístico), muitos apartamentos não têm espaço para uma máquina de lavar, então um ambiente convidativo e interativo pode ser interessante. Discutimos também sobre os diferentes costumes entre Brasil e Alemanha no quesito conhecer pessoas. Mesmo os brasileiros sendo normalmente mais abertos a fazer amizades, em cidades grandes essa diferença pareceu não ser tão evidente. 
AQUINO, M. - Projeto Novela

Desse modo, a abertura para discussões sobre as formas de interação, fez com que os alunos refletissem sobre a validade de diferentes perspectivas, dependendo do contexto sociocultural. Foi possível notar a quebra de preconceitos e clichês da cultura alemã, e a reflexão das realidades sociais e culturais dos dois países, ou ainda melhor, de cidades grandes, como Munique e São Paulo.

Conhecemos nessa lição os personagens Max e Lena, futuros protagonistas da novela. Eles se conheceram no Café Waschsalon, Max nunca havia lavado roupa e Lena, ao notar sua dificuldade, oferece ajuda. A partir desse primeiro encontro, os personagens se aproximam cada vez mais. Com a intenção de dar continuidade a essa história, organizamos o projeto em narrativas semelhantes às telenovelas, onde os estudantes criavam episódios em alemão, nos quais envolviam a aventura amorosa entre Max e Lena.

Foi incentivada uma postura independente dos alunos com relação às ferramentas e linguagem escolhidas para o projeto. O gênero mais ocorrente foi quadrinhos, no entanto, também foram utilizados vídeos da internet, onde os alunos fizeram a dublagem dos diálogos, produção de animação, textos em forma de diálogos, WhatsApp e até a composição de uma música. A escolha dos diferentes materiais demonstra a importância da inclusão dos alunos como (co)autores da aprendizagem.

Apresentaremos a seguir a descrição e alguns exemplos dos 8 episódios da novela.

Episódio 1: O primeiro grupo tinha a tarefa de continuar a história oferecida pelo livro didático, o encontro na lavanderia e o início da amizade entre eles. O capítulo foi desenvolvido por meio de um quadrinho. Na primeira cena eles se encontram na lavanderia. Na próxima cena Max envia uma mensagem de texto (SMS) convidando Lena para um concerto que aconteceria no mesmo local. Lena não responde, mas acaba aceitando o convite pessoalmente. Já no evento, Lena conta a Max que o guitarrista, Julien, é seu ex-namorado. Ao final do show Julien convida-os, insistentemente, para uma festa em sua casa, causando um desconforto entre os personagens. 
AQUINO, M. - Projeto Novela
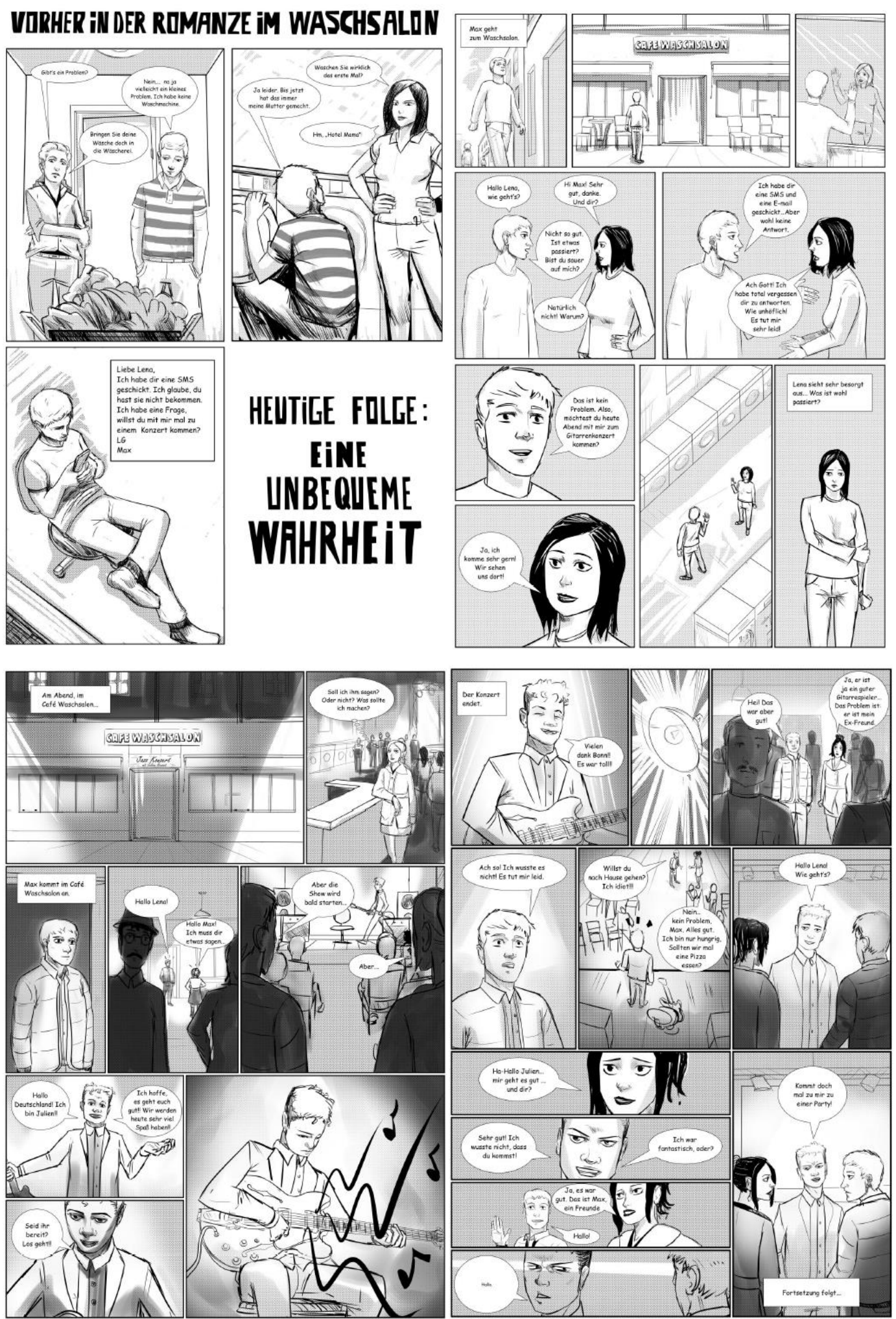

Figura 1: Episódio 1 da novela Fonte: alunos, Grupo 1

Grupo 2: O segundo grupo também produziu um quadrinho, no entanto, usando imagens retiradas da internet. $\mathrm{O}$ episódio descreve os personagens na festa na casa de Julien. Uma nova personagem é introduzida, Chantal, irmã de Julien, que desenvolve 
AQUINO, M. - Projeto Novela

interesse por Max. Chantal é descrita como uma personagem irritante e insistente, que exagera na proximidade com Max, o separando de Lena na festa, além de fazer perguntas desconfortáveis para a ex-cunhada. Julien também procura em diversos momentos chamar a atenção de Lena. Max e Lena passam um bom tempo afastados, mas ao final conversam e decidem ir embora comer algo, pois o clima não estava agradável e eles queriam ficar sozinhos. A última imagem do capítulo mostra os personagens indo embora juntos e sentados no café da lavanderia.

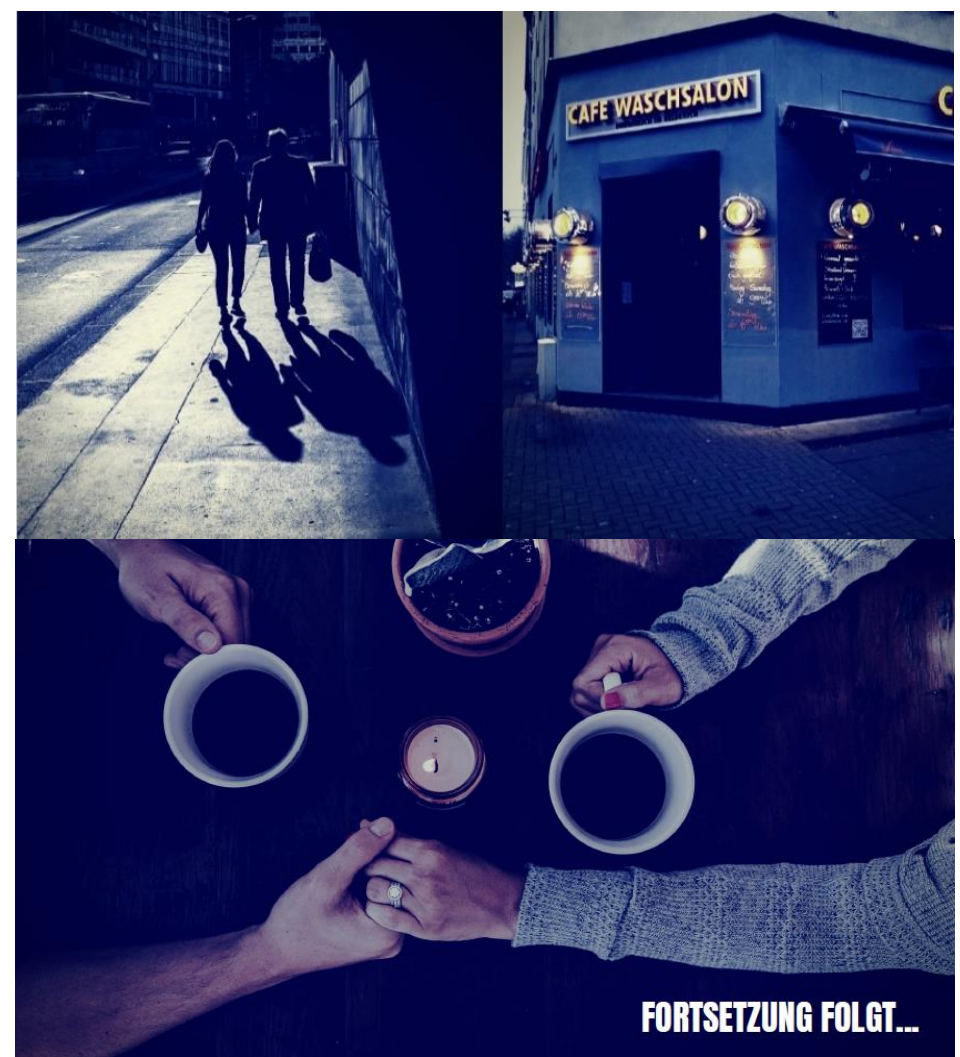

Figura 2: Últimas cenas do episódio 2 da novela Fonte: alunos, Grupo 2

Grupo 3: O terceiro grupo apresentou um vídeo animado. Este episódio é dividido em três cenas. Na primeira cena, ainda na festa, Chantal conversa com Julien acerca de um plano para separar Lexa e Max. Ela está bêbada e decide ir embora dirigindo, mesmo com o irmão insistindo para que ela não o faça. No segundo quadro, Max e Lena terminam de tomar café na lavanderia e se preparam para ir embora. Depois de se despedirem, Lena vai atravessar a rua, quando um carro avança em sua direção e a atropela. No terceiro quadro vemos Chantal chorando e confessando ao irmão que algo horrível havia acontecido, um acidente. 
AQUINO, M. - Projeto Novela

Grupo 4: No quarto capítulo Lena está hospitalizada, em coma. Max a visita com frequência e decide cantar uma música em sua homenagem. Dois dos alunos do grupo eram estudantes de música e compuseram uma canção para o projeto. Além da apresentação da leitura da cena no hospital, os alunos trouxeram instrumentos e tocaram a seguinte canção:

Lena, sei gut jetzt mein lieber Schatz

Gute besserung ist es, was ich dir sagen möchte.

Du bist zu schön für dieses Krankenhaus

Oh liebe Lena, du bist meine süße Maus

Lena, als ich dich im Waschsalon getroffen habe

Verlor ich die Atmung

Du bist zu schön für dieses Krankenhaus

Oh liebe Lena du bist meine süße Maus

Mein ganzes Leben warte ich auf dich

Ich bin sicher, du bist für mich gemacht

Bitte sag mir nur ein Wort

Und geh niemals weg

Ich habe mich in dich verliebt

Oh, Lena, Ich habe mich in dich verliebt ${ }^{7}$

Com a música, Max confessa seu amor por Lena, e em seguida percebe que ela começa a movimentar os dedos. O episódio termina após esse momento dramático.

Grupo 5: Esse grupo também utilizou sequências de imagens retiradas da internet para a composição da história, além de tocar a música do grupo anterior. Nesse episódio Lena está com Chantal na lavanderia e sonha com as histórias dos capítulos anteriores, ou seja, que havia conhecido um rapaz, sofrido um acidente, que ele a visitava no hospital e um dia cantava uma música para ela (Gruppe Vier, fazendo referência ao grupo 4). Lena

\footnotetext{
${ }^{7}$ Tradução da autora: Lena, minha querida, fique bem agora / Melhoras é o que eu quero te dizer / Você é linda demais para esse hospital / Oh querida Lena, você é meu docinho / Lena, quando te conheci na lavanderia / Eu perdi o fôlego / Você é linda demais para esse hospital / Oh, querida Lena, você é meu docinho / Eu esperei por você toda a minha vida / Tenho certeza que você foi feita para mim / Por favor, me diga apenas uma palavra / E nunca vá embora / Eu me apaixonei por você / Oh, Lena, eu me apaixonei por você.
} 
AQUINO, M. - Projeto Novela

relata seu o sonho a Chantal e, ao recolher suas roupas da máquina, percebe que foram trocadas. Ela reclama para o atendente e descobre que as roupas que ali estavam pertenciam a um rapaz chamado Max. Lena pede, então, o endereço de Max para realizar a troca das roupas.
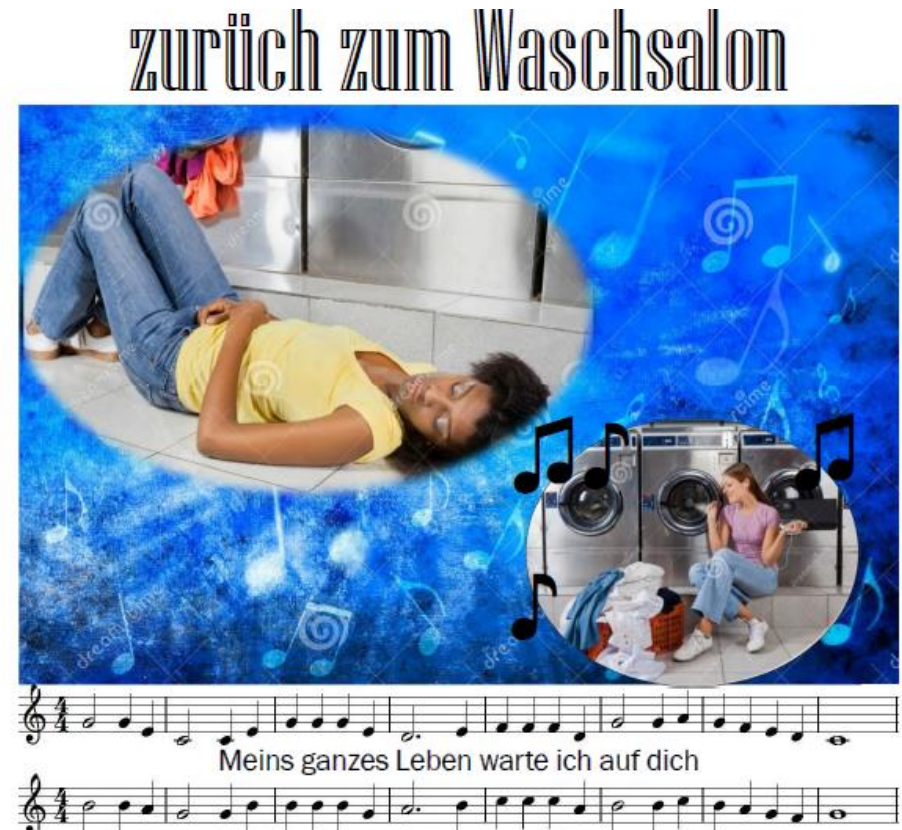

Ich bin sicher, du bist für mich gemacht

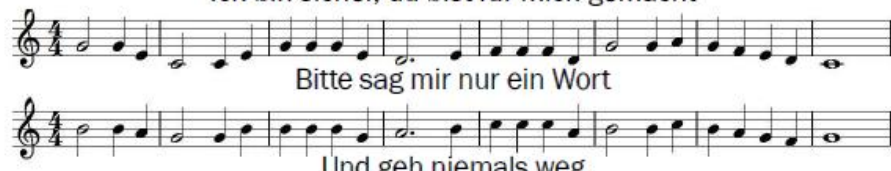

Und geh niemals weg

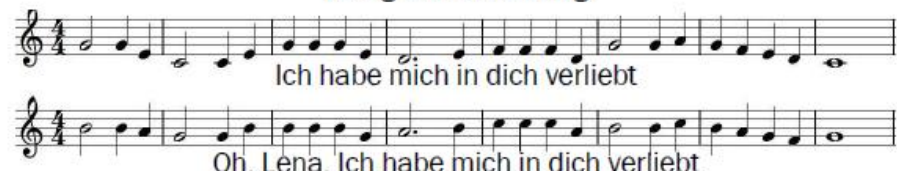

Figura 3: Primeira página do episódio 5 da novela Fonte: alunos, Grupo 5

Grupo 6: O sexto grupo utilizou um vídeo de uma cena da série de televisão norteamericana Gossip Girl e dublou em alemão as passagens do texto, sincronizando-as com as imagens, movimentos e personalidades dos personagens da série. Nesse episódio Lena vai até a casa de Max, mas se esquece de levar as roupas, fazendo com que eles precisem marcar outro encontro. Inicialmente eles pareceram não se dar muito bem, Lena estava irritada com a troca e Max tratou o assunto com ironia. Mesmo assim, surge um interesse de aproximação, e eles combinam de se encontrar em uma pizzaria para conversar e realizar a troca da roupa. 
AQUINO, M. - Projeto Novela

Grupo 7: Esse grupo realizou uma leitura dramática do diálogo. O capítulo descreve os personagens na pizzaria, conversando descontraidamente. Então entra na cena uma mulher com dois filhos dizendo ser a esposa de Max, fato que ele confirma. Acontece uma discussão acirrada entre os personagens, quando o telefone de Lena toca. Não sabemos o que aconteceu, mas ao desligar o telefonema ela diz, bastante preocupada, que precisaria ir embora urgentemente. O episódio é finalizado com a dúvida do que havia acontecido, tanto com relação à briga quanto ao telefonema.

Grupo 8: Coube a esse grupo juntar todos os acontecimentos dos episódios anteriores e finalizar o projeto da novela. Os componentes do grupo escolheram usar dois materiais, cenas do filme norte-americano Homem-Aranha, no qual realizaram legendas em alemão, e uma gravação em vídeo da tela de um celular durante uma conversa no aplicativo WhatsApp.

O episódio é dividido em duas cenas, na primeira (com as imagens do filme) Lena conversa com Max, no café da lavanderia, sobre os acontecimentos do capítulo anterior. Tudo não passou de uma brincadeira orquestrada por Chantal para surpreendê-la. Além de haver convencido Max a pregar uma peça em Lena (com o aparecimento da suposta mulher e filhos), foi ela quem realizou a ligação urgente, a qual não passava de um pretexto para convidar Lena à sua própria festa surpresa. Quando estão próximos de declarar o amor, um carro surge na vitrine e Max, que era o Homem-Aranha, salva a vida de Lena, revelando sua identidade secreta de super-herói.

Na última cena vemos o vídeo da tela do celular de Lena, que conversa com Chantal. Ela perdoa a amiga pela brincadeira infeliz e diz que vai se casar com Max, mostrando a foto do seu anel de noivado. 
AQuINO, M. - Projeto Novela

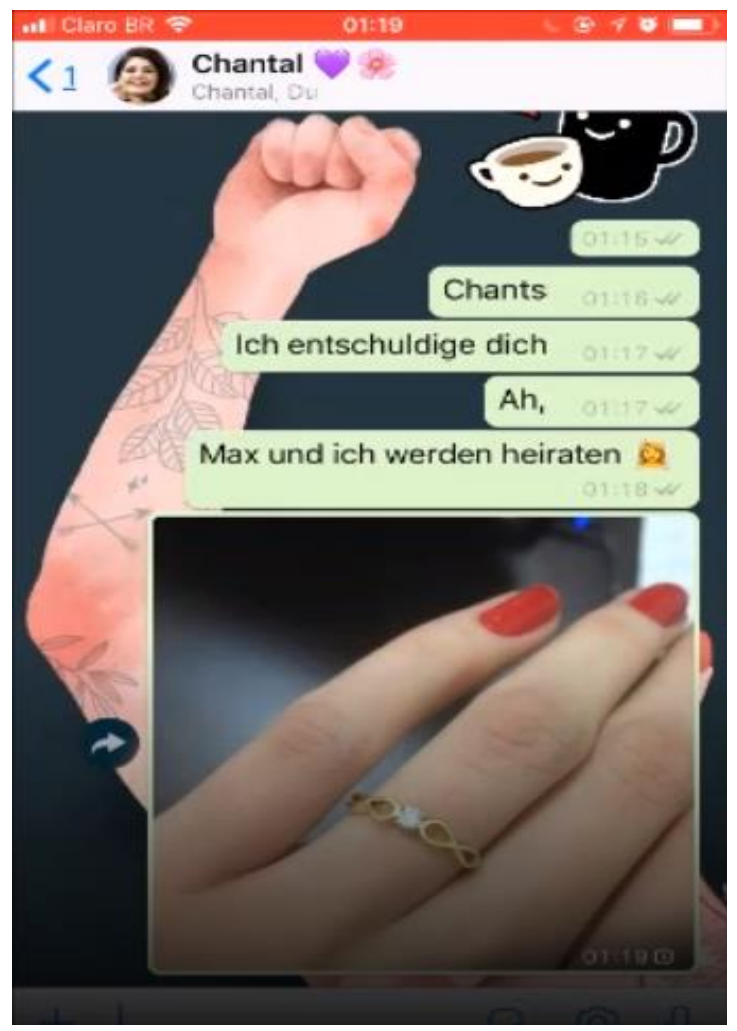

Figura 4: Últimas cenas do episódio 8 da novela Fonte: alunos, Grupo 8

Podemos evidenciar, primeiramente, que os alunos usaram a criatividade, suas experiências e interesses para o desenvolvimento dos projetos. A linguagem e os materiais escolhidos refletiam os seus gosto, costume e personalidade. Com relação às questões interculturais vimos uma mistura entre situações típicas de novelas brasileiras (como drama e exageros) e a lavanderia/café alemã. Além disso, sentimos a influência de outras culturas, com o uso de filmes e séries norte-americanos. Também foram utilizadas novas mídias, como o programa de desenho de quadrinhos, as animações, trocas de SMS, imagens e vídeos retirados da internet e WhatsApp.

Além do uso de linguagem autêntica e informal, foram desenvolvidos conteúdos gramaticais, como verbos modais, conjugação no presente, perfeito e pretérito, conjunções, posição dos elementos na oração, entre outros. Por esse ângulo, os projetos trazem variedade ao ensino de ALE e podem ser integrados em diferentes níveis de aprendizado. Para os alunos, essa tarefa ofereceu a oportunidade de desenvolver criativamente o aprendizado, e colocar seus conhecimentos e habilidades adquiridos em prática. 


\section{Conclusão}

Ensinar uma LE é principalmente promover o acesso a uma nova cultura. Ao abordar aspectos interculturais, o professor instiga a curiosidade e a motivação dos alunos para aprender e conhecer a cultura-alvo, bem como descobrir e desconstruir preconceitos interculturais. Neste trabalho apresentamos o desenvolvimento do projeto Novela em sala de aula de ALE como estratégia didática para a mediação de habilidades comunicativas e interculturais. Nesse sentido, projetos similares podem ser realizados em aulas de LE, levando-se em consideração as necessidades específicas de cada grupo e contexto de aquisição.

Outros fatores relevantes introduzidos por esse projeto são o senso de (co)participação nas decisões sobre os processos de aprendizagem, bem como o sentimento de pertinência, coesão e percepção compartilhada de realização, aprofundando laços sociais entre os membros do grupo em prol de um resultado comum. Em conjunto atinge-se uma interação significativa onde a escolha de conteúdos relevantes são os critérios centrais no planejamento de atividades comunicativas e interculturais (KUMARAVADIVELU 2006: 134). Nessa perspectiva, o projeto também cria condições para a aprendizagem através de uma abordagem orientada por objetivos, isto é, o uso da linguagem para alcançar interações concretas e reflexões interculturais.

De maneira geral, pode-se ainda concluir que os alunos foram beneficiados com o projeto, pois eles se envolveram ativamente no processo da aprendizagem. O clima em sala de aula melhorou, o projeto permitiu um ambiente de troca, fazendo com que os estudantes se sentissem cada vez mais confiantes ao utilizar de forma prática o conhecimento adquirido.

Por fim, sabendo que o treinamento para habilidades individuais é cada vez mais substituído pela aprendizagem integrativa, mediações com projetos podem auxiliar o difícil trabalho do professor de desenvolver estratégias e atividades voltadas para as necessidades dos alunos. Por esse ponto de vista, o projeto novela propiciou o uso da língua alemã em um meio de comunicação autêntico, permitindo que todos os participantes aplicassem seus conhecimentos e identificassem individualmente suas capacidades, déficits e interesses, contribuindo para uma aprendizagem autônoma. 


\section{Referências bibliográficas}

AQuino, M. O questionário como ferramenta de ensino das partículas modais alemãs. Pandaemonium Germanicum, São Paulo, v. 20, n. 32, 2017, p. 156-179.

AQUINO, M. Guia de sobrevivência: desenvolvendo estratégias comunicativas e socioculturais em aulas de PLA. Linguagem \& Ensino, Pelotas, v. 21, n. 1, 2018, p. 273-293.

Austin, J. L. How to do things with words. Cambridge: Harvard University Press, 1962.

BRAUN, B et al. DaF kompakt neu Al: Kurs- und Übungsbuch. Stuttgart: Klett, 2016.

BRAUN, B et al. DaF kompakt neu A2: Kurs- und Übungsbuch. Stuttgart: Klett, 2016.

CAlzA, R. O que é telenovela. São Paulo: Brasiliense, 1996.

KRUMM, H. Unterrichtsprojekte: praktisches Lernen im Deutschunterricht. Fremdsprache Deutsch, Berlin, n. 4, 1991, p. 4-8.

KÜHN, P. Materialien für das Wortschatzlehren und -lernen. In: KRUMM, Hans-Jürgen et al (org.). Deutsch als Fremd- und Zweitsprache: ein internationales Handbuch. 2. ed. Berlin: De Gruyter, 2010, p. 1252-1258.

KumaraVADIVELU, B. Understanding Language Teaching: from method to post-method. New Jersey: Lawrence Erlbaum Associates, 2006.

MuraKami, M. H. Da fantasia ao transmídia: modernização do gênero telenovela brasileira. Tese (Doutorado em Meios e Processos Audiovisuais) - Universidade de São Paulo, São Paulo, 2015.

RÖSLER, D. Deutsch als Fremdsprache: eine Einführung. Stuttgart: Verlag J.B. Metzler, 2012.

SCHART, M.; LEGUTKE, M. Lehrkompetenz und Unterrichtsgestaltung. Berlin: Klett, 2012.

SCHNEIDER, M. N. Abordagens de ensino e aprendizagem de línguas: comunicativa e intercultural. Contingentia, Porto Alegre, v. 5, n. 1, 2010, p. 68-75.

VigOTSKI, L. S. A formação social da mente: o desenvolvimento dos processos psicológicos superiores. Trad. de José Cipolia Neto, Luís Silveira Menna Barreto, Solange Castro Afeche. 6. ed. São Paulo: Martins Fontes, 1998.

WEISSENBERG, J. Sprachbedarfsermittlung im berufsbezogenen Unterricht Deutsch als Zweitesprache. Hamburg: Passage, 2012. 